\title{
Research of influence of vibration impacts of chimes on the steeples of St. Isaac's Cathedral (Saint Petersburg) after reconstruction thereof
}

\author{
Elena E. Smirnova ${ }^{1, *}$, Sergey N. Savin ${ }^{1}$, and Denis V. Larin ${ }^{1}$ \\ ${ }^{1}$ Saint Petersburg State University of Architecture and Civil Engineering, 190005 Vtoraja Krasnoarmejskaja ul. 4, St. Petersburg, \\ Russia
}

\begin{abstract}
This article gives consideration to the ways of solving a problem of ensuring safety of buildings and structures in use provided their operating conditions have changed. The assessment of possible consequences of bells installation on the steeples of St. Isaac's Cathedral is given as an illustration. The measurements of vibrations with simultaneous assessment of robustness and bearing capability of the brickwork have shown that the vibration impact of chimes of heavy bells can not adversely affect the bearing structures of the bell towers. However, there is always a risk of such adverse affect on the structure of the bell tower and stability of soils at its base. It is offered, therefore, to carry out investigation before the beginning of reconstruction using the structure model, which makes it possible to give consideration to the impact of «new» loads to exclude any possible emergency situation at the objects being reconstructed.
\end{abstract}

\section{Introduction}

Due to reconstruction and restoration of the original guise of the landmarked buildings the investigators are facing the problems of assessing possible adverse consequences of such sorts of work in the recent years. The most problematic are the works requiring dismantling of the bearing and fencing structures built into original scheme. Kronstadt Naval Cathedral, building of the church of Transfiguration of Jesus and other significant historical buildings have become the examples of such sort of objects for Saint Petersburg. The builders and architects have succeeded to successfully solve these complex problems using the up-to-date methods of technical diagnostics and calculation by means of three-dimensional finite-element models [1-2].

Another type of works implies a revival of ensembles of bells on the steeples [3-4]. In order to assess possible adverse consequences of these actions, it is necessary to take into account not only the new load emerging in the structures not being used for direct purpose for long, but the possible consequences of vibration impact on the soils of bases of structures.

A group of researchers (including authors of this article) under the leadership of I.V. Sitnikov from the researchand-development center No.26 of the Ministry of Defense of the Russian Federation together with the specialists of Saint-Petersburg Railway Engineering and Transportation University have conducted measurements of vibrations caused by the chimes of the bell tower of St. Isaac's Cathedral (Saint Petersburg) and analyzed the possible consequences thereof within a period of 2013-2015.

The measurements of vibrations with simultaneous determination of the robustness of brickwork of the bearing structures of steeples have been performed in two stages: in November-December 2015 in the course of installation of a big ten-ton polylinear bell on the North-eastern steeple and in December 2016 after installation of 17-ton bell on the north-western steeple of St. Isaac's Cathedral.

The level of vibrations at the bearing structures of steeples, parameters of low-frequency dynamic impacts occurring in case of bells swinging, and strength characteristics of the stonework have been measured in the process of investigations.

The acquired results have been analyzed and compared with the existing requirements of standards [5-8] with a view to exceedance of actual loads.

\section{Materials and Methods}

The oscillations were recorded using a research measuring complex, which allows measurements of the RMS (rootmean-square error value) of vibration velocity, relative magnitude of vibration displacement, relative displacement and

\footnotetext{
* Corresponding author: esmirnovae@yandex.ru
} 
linear displacement and indication of the measured parameters. It consists of measuring sensors of CJSC Geoakustika A1612 and A1633, and KV-12 (Fig. 1-2). The piezoelectric A1612 and A1633 single-component accelerometers are designed to convert accelerations acting along their measuring axes into proportional electrical signals; accelerometers are used as primary transducers as part of vibration measuring systems, and can also be used for measuring low level vibrations. In A1612 units, a package of unloaded bimorph disks with central fastening is used as a sensitive element; sensitive elements A1612 and A1633 are connected to preamplifiers, which form the main characteristics (AFC amplitude-frequency characteristic, conversion factor, supply voltage, output impedance, etc.), which allows accelerometers to be adapted to the solution of a specific measurement task.

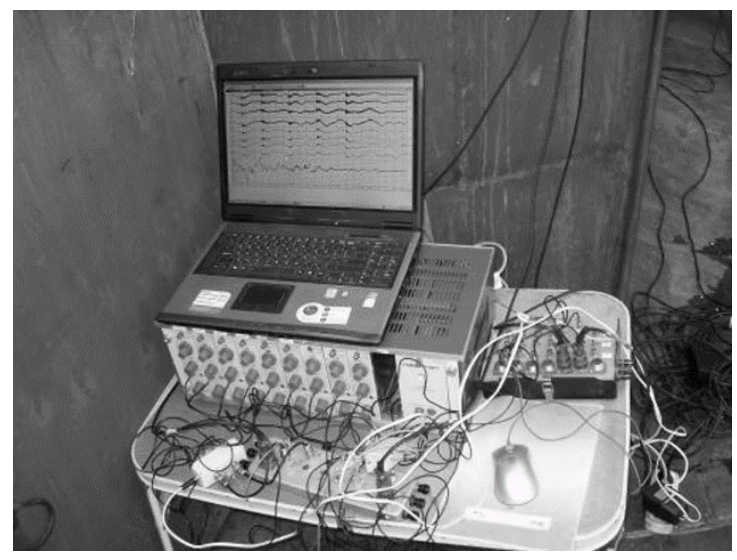

Fig. 1. Measurement Sensors A1612 and A1633 of Geoakustika CJSC (operating frequency range - from 0.2 to $400 \mathrm{~Hz}$; amplification factor - up to $100 \mathrm{mV} / \mathrm{m} / \mathrm{s}^{2}$ ).

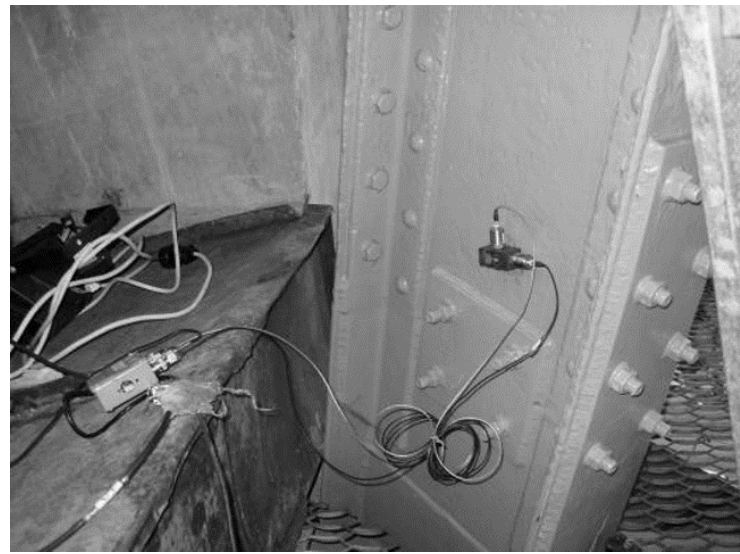

Fig. 2. Measurement Sensor KV-12 of Geoakustika CJSC (sensitivity - $300 \mathrm{mv} / \mathrm{ms}^{2}$; frequency range - up to $400 \mathrm{~Hz}$ ).

The broad-band amplifier Robotron is also an integral part of the system. It has the following measurement modes: acceleration, speed, displacement; its amplification ranges from 1 to 10,000 with a step change in $10 \mathrm{~dB}$ steps; frequency range from $1 \mathrm{~Hz}$ to $20 \mathrm{kHz}$; the number of measurement channels is at least $8 ; 220 \mathrm{~V}$ or DC battery power supply;

- Analog-to-digital converter (ADC). Its characteristics are as follows: the number of channels is at least 8 , the bit depth is at least 12 bits, the ranges of measured signals are $\pm 5.12 \mathrm{~V}, 2.56 \mathrm{~V}, 1.024 \mathrm{~V}$; maximum conversion frequency $-300 \mathrm{kHz} /$ channel.

- Measurement cables;

- Portable computer is equipped with software for input and processing of measurement information.

The means of excitation of oscillations (before installation of 17-ton bell) - external impulse (special strike). Such a blow is applied in the upper part of the object, for example, with a load of up to $50 \mathrm{~kg}$.

The means of excitation of oscillations (after installation) - bell ringing.

The methodology of determining level of vibrations of building structures includes the following operations:

- registration of oscillations;

- calculation of Fourier spectra thereof;

- analysis of Fourier spectra with the aim of identifying resonance peaks corresponding to the level of vibrations and oscillations in a wide range of frequencies.

\section{Results}

In case of necessity of assessing consequences of vibration load impact on the bearing structures the dynamic parameters thereof have been determined in the way of: 
- obtaining pulsed implementations of identified resonance peaks for every free vibration mode by means of inverse Fourier transformation;

- identification and graphical representation of various waveforms.

The vibrations have been recorded «under load» in the process of chiming.

The dynamic parameters of the «beams-bearing structures of bell tower» system have been determined by analyzing the structures response to the pulsed load. The obtained frequencies and waveforms have been analyzed, response spectra determined and values of accelerations and velocities in the targeted range of frequencies (up to $50 \mathrm{~Hz}$ ). The photo and scheme of measurements at the structures of the North-western bell tower, where the vibrations have been registered and the brickwork probed, are shown in Fig. 3 and 4:

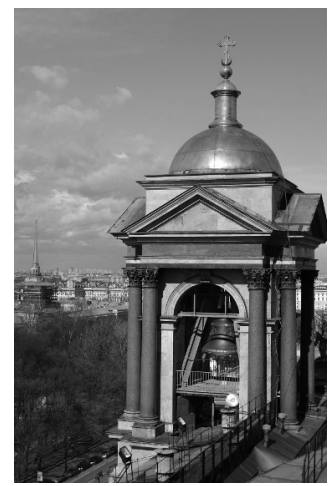

Fig. 3. South-eastern steeple with the installed bells.

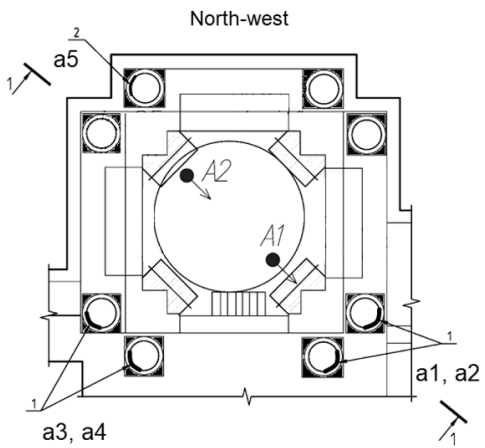

Fig. 4. Scheme of installing sensors for measuring vibrations and through probing (A1 and A2 - accelerometers. Digits 1 and 2 in figure designate places of brickwork probing - a1, a2, a3, a4, a5.

The measurement sensors have been arranged on the bearing structures. Results of frequency response analysis of vibrations are presented in Fig. 5 and 6.

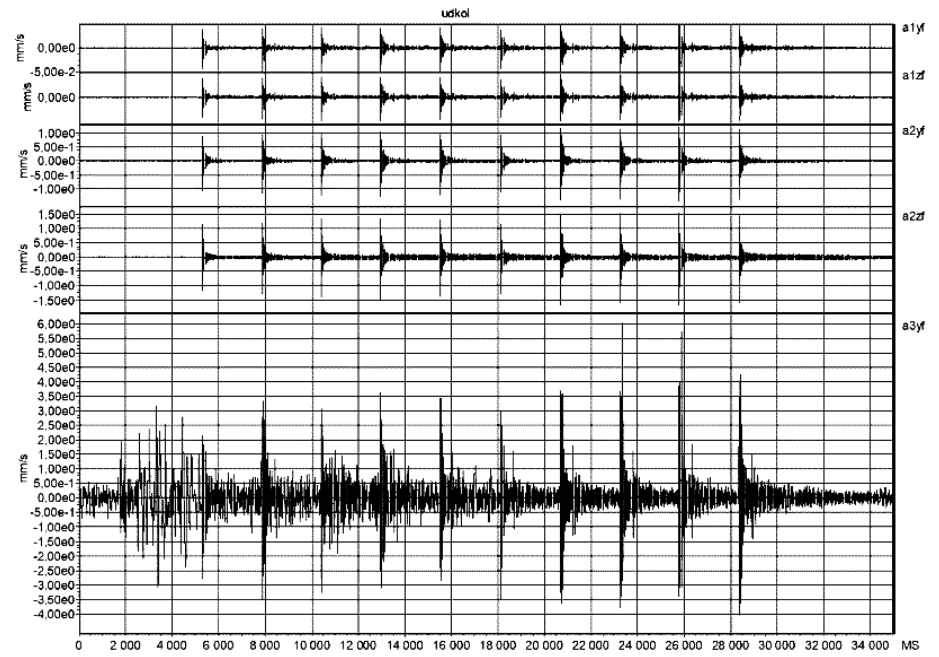

Fig. 5. Fragment of the recording of the primary response signal to the beats of the 17-ton bell. Vibrations of structures at the points of sensors installation are distinctly seen. The picture shows the largest vibrations ( 5 sensors). 


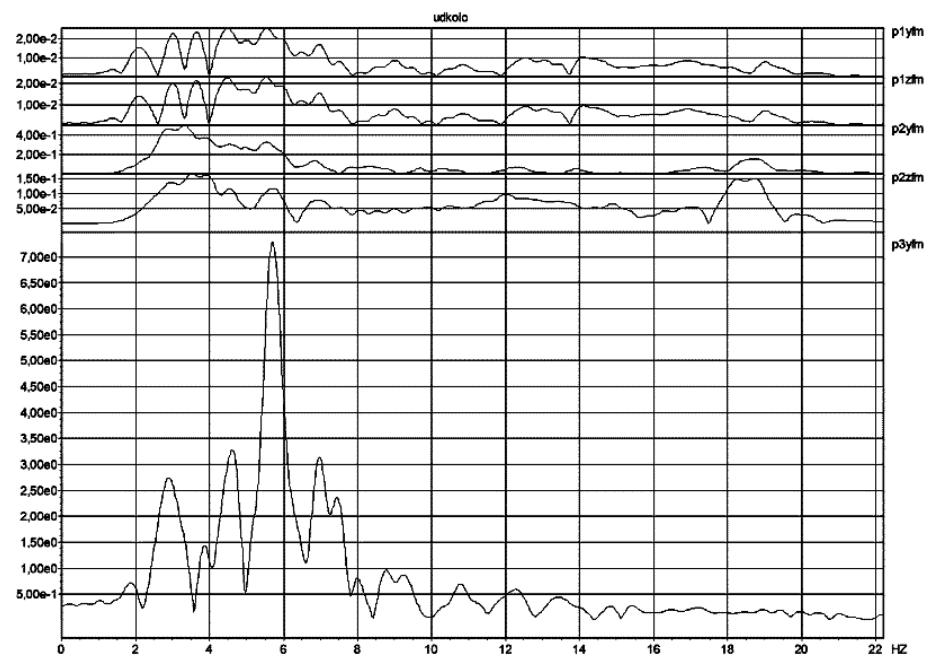

Fig. 6. Spectra obtained in the software signal processing environment with emphasizing of vibration peaks. Reaction to the strike of the 17-ton bell (short section). Sensor numbers are shown on the vertical axis to the right, on the horizontal axis - time in milliseconds. The amplitude of accelerations on each sensor, $\mathrm{m} / \mathrm{s}^{2}-$ on the vertical axis to the left.

The maximum registered velocity at sensors A3 and A4 (metal structures) amounted to $3 \mathrm{~mm} / \mathrm{s}$, and at sensors A1 and A2 (at brick pillars) $-1.5 \mathrm{~mm} / \mathrm{s}$. In this case displacements amounted to not more than $15 \mu \mathrm{m}$ at the metal frame and $2.1 \mu \mathrm{m}-$ in the brickwork (Fig. 7).

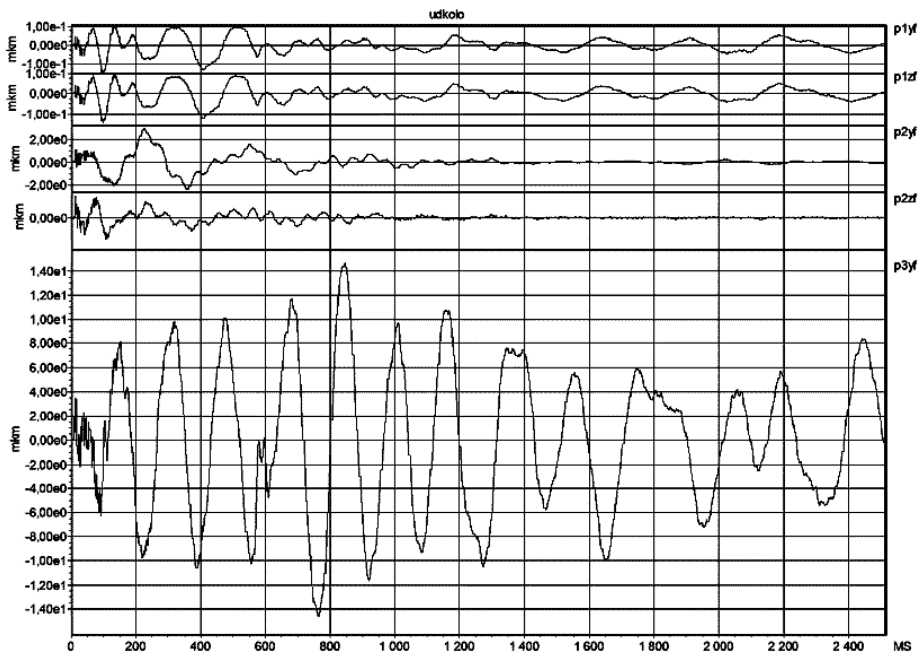

Fig. 7. Records of values when the structure is displaced along the horizontal axis, according to sensors, when a 17-ton bell is struck.

The analysis of amplitude of vibrations and spectra of oscillations of the system shows that the maximum values of acceleration and velocity in the range of frequencies posing a danger to the bearing structures (up to $50 \mathrm{~Hz}$ ) do not exceed the values at the walls - up to $2.0 \mathrm{~m} / \mathrm{s}^{2}$, at that, the vibration velocity of the brick pillars does not exceed 0.9 $\mathrm{mm} / \mathrm{s}$, while the displacement is up to $2.5 \mu \mathrm{m}$.

The maximum registered velocity has amounted to $10 \mathrm{~mm} / \mathrm{s}$. In this case the displacements have not exceeded 15 $\mu \mathrm{m}$ at the metal frame and up to $1 \mu \mathrm{m}$ - in the brickwork.

The values of accelerations from vibrations occurring during bell tower usage are lower than it is permitted by GOST sanitary standards (2010) for office premises for the steeple structures [5].

Apparently, it is difficult to expect any considerable vibrations at the structure base with the registered values of vibrations and displacements at the bell tower structures close to the attachment points of suspensions.

The settlements of the buildings foundations in weak soils reach $2 \mathrm{~mm} /$ year according to data of SN (1997) and TSN (2004) [6-7] under working conditions at the vibration velocities about $400 \mu \mathrm{m} / \mathrm{s}$, while light damages of old buildings, separation of limewash, chipping of small pieces of plaster are possible at the vibration level of $1,200 \mu \mathrm{m} / \mathrm{s}$.

The analysis of requirements of GOST (2007) [8] has made it possible to set a threshold value of vibration impact on the soil ground by the velocity of oscillations of $73 \mathrm{~dB}$ or $225 \mu \mathrm{m} / \mathrm{s}$. In case this level is exceeded it will be necessary to carry out special engineering measures to reduce vibration negative consequences for maintaining the bearing capabilities of soils, reliable and trouble-free operation of engineering structures and provision of people's optimal vital activities. Even though, no registrations of soil oscillations at the base have been carried out while investigating vibration oscillations of the bell tower during chimes, it is apparent that the actual values of velocities and displacements are significantly below the threshold value of vibration impact, which can adversely affect the soil ground $[9-10,3]$. 
Vibrations from ringing were recorded in the audio frequency range. Since the response of the structures to the external vibration effect from the bells and vibrations of the bells themselves was investigated, extremely low amplitudes of recorded vibrations were detected in the frequency range. Their detailed analysis revealed the inessential value of the Fourier spectra (Fig. 8).
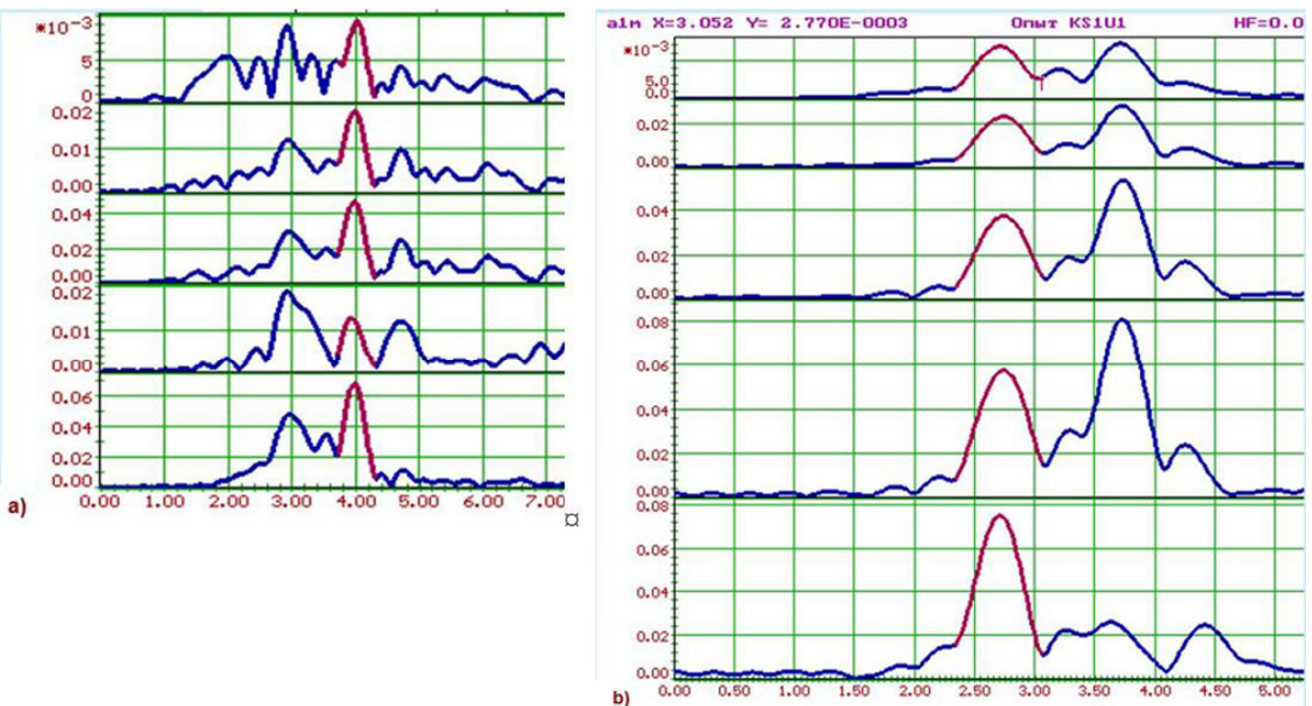

Fig. 8. Analysis of Fourier spectra in order to highlight resonant peaks corresponding to the level of vibrations and vibrations in a wide frequency range is given. Amplitude spectrum. The first tone (mode). Vertical range, transverse direction: a) 1 tone $-3.08 \mathrm{~Hz}$ (measurements in 2015); b) 1 tone $-2.7 \mathrm{~Hz}$ (measurements of 2016).

Since the largest peaks showed insignificant vibrations, the overlap of the Fourier spectra was not considered, due to the low values of vibrations (free vibrations) of the supporting structures and the foundation.

Thus the effect of the bell tower resonance swinging is not observed during multiple chimes, since the frequencies of clappers swinging and the natural frequency bending oscillations of the bell tower differ significantly.

The maximum oscillations in the course of regular work of bells occur in the steel frame structures. However, the pulse transmitted to the suspension beam and further to the bell tower is quite insignificant. The measurements of vibratory oscillations have shown that the maximum values of velocity and acceleration in the range of frequencies posing a danger to the bearing structures (up to $50 \mathrm{~Hz}$ ) do not exceed the values at the walls - up to $2.0 \mathrm{~m} / \mathrm{s}^{2}$, at that, the vibration velocity of the brick pillars does not exceed $0.9 \mathrm{~mm} / \mathrm{s}$, while the displacements are up to $2.5 \mu \mathrm{m}$.

\section{Discussion}

Perhaps, further reasoning does not specifically emphasize the carried out analysis of vibration caused by the bells. However, it is necessary to take into account vibro-creeping (at least in the theoretical aspect) for estimating and calculating the sediment settlement under St. Isaac's Cathedral. This is relevant because there is a potential danger for the soil carrying capacity of the oscillations excited by the ringing of heavy bells.

The adverse impact sets in because of uneven settlement, when the soil becomes substantially non-uniform by its properties. It is important to take into consideration that the process of foundation settlement corresponds to quite a durable change, therefore, it is necessary to establish an instrumental monitoring and take the due engineering decisions for soils stabilization.

The vibration impact of chimes can weaken the bearing capability of soils at the bell tower base. It is common knowledge that the durable vibration loads on soil can bring about its nonreversible deformations, which will get gradually accumulated and can reach significant magnitudes. These deformations can bring about differential settlements of foundation, which will entail deformation of the elements of building structures, damage and destruction thereof.

Therefore, it is always desirable to look for the ways of reducing vibration loads on the bell towers. In this regard the heavy bells have been suspended in Christ the Saviour Cathedral using resilient suspensions with damping oscillations of the bells. In case of clapper verberation the bell skirt is in a position to move, which reduces the pulse being transferred from the strike to the brickwork of walls. They have chosen a different way in the Holy Trinity-St. Sergius Lavra. The specialists of Khrunichev Scientific and Production Center (division of Roskosmos (the Russian Federal Space Agency) have developed a clapper balanced with respect to the inertia moment for the Tsar Bell in the Kremlin of Moscow with such masses distribution that has many times reduced the pulse transmitted to the suspension beam and further, to the bell tower. The measurements of vibration oscillations have demonstrated that the amplitude of the bell tower horizontal oscillations has decreased 4 times with the balanced clapper as compared with a clapper of a traditional shape. 
Generally, the bell towers, where the unique heavy bells are installed, are the famous historical sites. Historically, the shadoof suspension system was used originally in Russia, when the bell-clapper hung freely, while the bell swung together with the beam (shaft) of a suspension. The bell touched the clapper to produce reverberation chimes. A metal rod of a rectangular section, a tie beam, which ends have been forged to become round and put into bearings corresponding to wooden bars with a steel strip on the top established the basis of the shadoof bells suspension system. The suchlike system of bells ringing has been preserved in the Pskov Monastery of the Caves. The most ancient tie beam of early XVIth century (1508) has been preserved in the Kremlin; it is used for suspension of «Medved» (Bear) bell (i.e. «howler») of mezzanine of the Kremlin Ivan the Great steeple (Fig. 9 and 10):

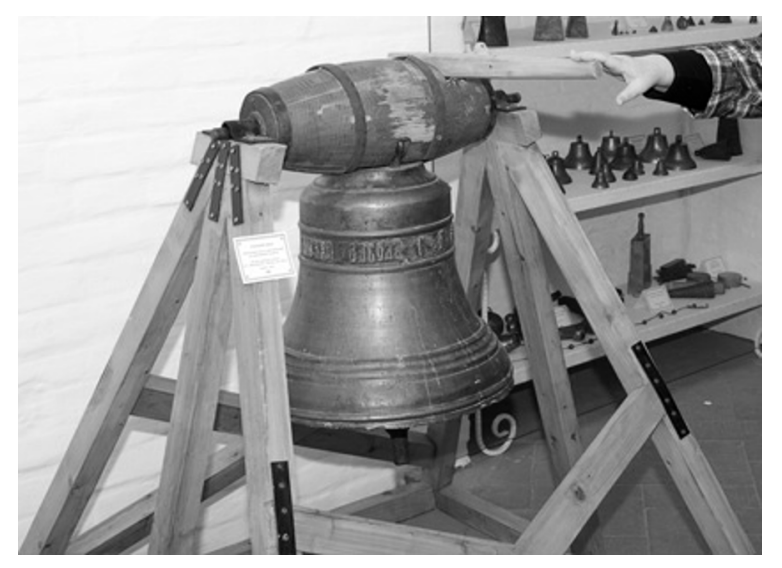

Fig. 9. Shadoof bell in the «English style», i.e. bell swings full-circle. If in early times bells were swung through a small arc, but by the 17th century in England it was common to find bells capable of swinging through $360^{\circ}$. A short lever used earlier for swinging the bell, became essentially longer and took a shape of a big stick attached perpendicularly with one end to a rotating shaft with the bell. A rope had been tied to the other stick end, which was pulled by a chimer standing at the church wall. The foregoing stick came to be called the «shadoof».

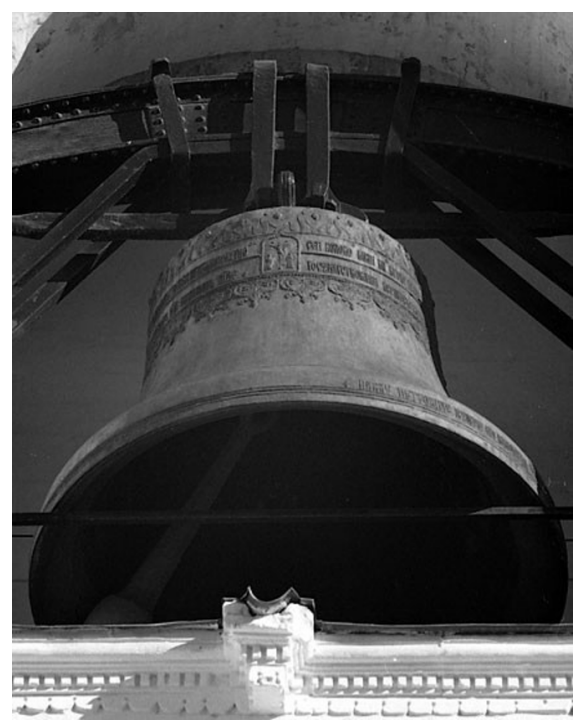

Fig. 10. Shadoof «Medved» bell of the Kremlin Ivan the Great Bell Tower.

A passive position of the clapper with respect to the bell body in the shadoof suspension was quite relevant during installation of small bells. But with the increase of the shadoof suspension bell weight, they have been replaced with freely-hanging bells. Many bells, including small and medium ones were suspended in XV-XVII centuries statically to wooden beams embedded into pylons of bell towers and steeples alongside with the shadoof suspension of bells and the chime was produced by swinging the clapper.

Swinging the clapper, the chimers succeeded to achieve more durable sound. The suspension of bells is to be designed so that to provide high amplitude of sound pressure after clapper verberation. For example, the craftsmen in the Kremlin pulled the forged tie beams at suspensions through the pairs of side bell eyelets and secured the beams with the clamps in the form of U-letter to the suspension beam. A sturdy suspension provided for the freedom of the bell swinging from the verberation (chimes «by clappers»). After visual inspection of old suspensions it became clear that in the course of time the tie beams and clamps have ceased to provide a respective freedom of bell swinging. It was not difficult to come to a conclusion that significant bending moments affected the eyelets of bells during chimes (they can cause the destruction of eyelets and subsequent falling). In the course of bell swinging the vibration levels at frequencies normally about $2 \mathrm{~Hz}$ may cause significant destruction [11]. The multiple examples of bells, including the bells in the Kremlin steeple, prove particularly this mechanism of bells wreckage. Besides, the enslaving suspension becomes a reason for intensive transmission of oscillations of the chiming bell to the suspension beam and further, to 
the bell tower walls. A pulse from the clapper verberation and from vibration of the sounding bell is transmitted at every clapper verberation against the bell skirt through the bell suspension system and through the suspension beam to the bell tower. These pulses provoke resilient waves, which propagate along the brickwork of walls up and down and cause the bell tower oscillations.

It is known that the amplitude of the bell tower horizontal oscillations depends on the clapper mass. The bells foundry men have strictly followed a tradition: there should be a proportion of 1:25 between the mass of a clapper and a bell. This proportion should be proven by the practice of using bells, wherefore, not infrequently the cracks appeared in the skirt, when the clapper mass is bigger, if the clapper mass is smaller; it produces the basic tone of singing, i.e. the undertone of low sound level. It proceeds therefrom that it is important to plot a dependence of oscillations amplitude not on the mass of clapper, but on the mass of bell (under standard conditions the dependence of amplitude of bell tower displacements from the bell mass shall be linear). However, the amplitude of oscillations velocity and the amplitude of displacements in case of multiple verberations is approximately a couple of times bigger than in case of a single verberation. Therefore, when ringing the bell (clapper verberations against both sides), the amplitude of horizontal oscillations increases with the increase of quantity of verberations and attains a condition of «saturation» with 11-12 verberations. In our case, when investigating the north-western steeple of St. Isaac's Cathedral, the maximum velocities of oscillations, maximum displacements and the values of frequency of spectral maximum for horizontal oscillations in the north-western direction obtained at different steeple levels when ringing the bells have been measured. Using experimental data, it is also possible to build a dependence of amplitude of oscillations on elevation points. The acquired full-scale data can be described as a parabolic dependence proving the bending character of oscillations [12].

The analysis of bell tower oscillations under wind loads has shown that this frequency is a natural frequency of the steeple bending oscillations. The multiple verberations rather than a single one are relevant for the bell tower. Therefore, it is possible to clang all heavy bells simultaneously. At that, a superposition of oscillations excited by every bell takes place. According to investigations the amplitude of oscillations is higher in this case than any oscillation from any individual bell, but it is lower than the sum of amplitudes. It is explained by the fact that the periods of swings of the clappers of heavy bells are different with respect to values and the verberations proceed non-synchronously. GOST (2007) «Vibration and shock» establishes the limiting velocities of oscillations of the base of structures in case of impulse actions thereupon, which may include the verberations too. The GOST values significantly exceed the registered velocities of oscillations of the base of the north-western steeple of St. Isaac's Cathedral during chimes.

It is also important to involve a theory of cyclic strain-induced creep for assessing and calculating soil settlements. According to formula:

$$
S=\alpha \sqrt{t}
$$

where, $S$ - settlements in mm, $a$ - intensity of cyclic strain-induced creep, $t-$ time in minutes. It equals $10^{-2} \div 10^{-1}$ $\mathrm{mm} / \sqrt{\mathrm{min}}$. for marshy soils with soil-bearing load of about $2 \mathrm{~kg} / \mathrm{cm}^{2}$ (such soil-bearing load is produced by the weight of the north-western steeple, including the cathedral base used for supporting it). This implies that the settlements can amount to $0.5 \div 0.05 \mathrm{~mm}$ during half an hour of chimes. In case of repeated impacts the settlements will get recommenced and summarized. A danger emerges not because of significant settlements, but rather due to irregularity owing to inhomogenuity of soil [10]. The obtained assessments of settlements show that they can not be ignored and it is reasonable to perform an annual leveling check of settlements of foundation or base of the bell tower.

\section{Conclusions}

In conclusion of the conducted investigations one can confirm that the vibrational impact of chimes of heavy bells with respect to the objects being considered can not adversely affect the bearing structures of the bell towers. This finding is proven out by already more than two years of successful operation of reconstructed objects. However, one should pay attention to the fact that the research of possible adverse consequences of bells installation works has been carried out already after changing «customary» conditions of operation. At that, there existed a probability of destruction or damage of the bearing structures as well as weakening of the base soils. Therefore, it is quite reasonable to recommend carrying out a definite type of investigations prior to beginning the restoration work: e.g., investigation of the bearing structures and building the mathematical model of the structure, which can be used for excluding possible emergency situations at the objects being reconstructed.

\section{References}

1. S. Savin \& V. Tsakalidis. The use of elastic oscillations of different wavelengths to evaluate the dynamic parameters of buildings and structures and assess the strength of materials of the building construction. COMPDYN 2015. Proceedings of the 5th International Conference on Computational Methods in Structural Dynamics and Earthquake Engineering Methods in Structural Dynamics and Earthquake Engineering, 5. 25-27 May 2015 Crete Island, Greece. M. Papadrakakis, V. Papadopoulos, V. Plevris (eds.). Hersonissos, Crete: National Technical University of Athens. P. 706-720 (2015) 
2. S.N. Savin. The use of elastic oscillations of different wavelengths to evaluate the dynamic parameters of buildings and structures and assess the strength of stone walls. Seysmostoykoye stroitel'stvo. Bezopasnost' sooruzheniy [Earthquake engineering. Constructions safety], 4, 43-55 (2017)

3. S. Savin \& E. Smirnova. Evaluation of mechanical safety of building structures using elastic vibrations varying in wavelength. World Applied Sciences Journal, 23(11), 1448-1454 (2013) DOI: 10.5829/idosi.wasj.2013.23.11.13161

4. A.V. Adushkin, A.I. Goncharov, V.I. Kulikov. Vibrokolebanija kolokol'ni pri kolokol'nom zvone [The vibrations of bell tower excited by bell ringing]. Dinamicheskiye protsessy v geosferakh [Dynamic processes in geospheres], 1, 172-180 (2010)

5. GOST (2010) Refractories and refractory raw materials. Methods of refractoriness determination - GOST R 53788-2010. Zdanija i sooruzhenija. Pravila obsledovanija i monitoringa tehnicheskogo sostojanija. Moscow: Standartinform (2010)

6. SN (1997). The sanitary norms of industrial vibration, vibration of residential and public buildings - SN 2.2.4/2.1.566-96. Proizvodstvennaya vibratsiya, vibratsiya v pomeshcheniyakh zhilykh i obshchestvennykh zdaniy. Minzdrav Rossii. Moscow: Minzdrav (1997)

7. TSN (2004). Designing the foundations of buildings and structures in St. Petersburg - TSN 50-302-2004. Proektirovanie fundamentov zdanij i sooruzhenij v Sankt-Peterburge. St. Petersburg, Strojizdat (2004)

8. GOST (2007) Vibration and shock. Vibration of buildings. Measurement of vibration and evaluation of its effects on structure - GOST R 52892-2007. Vibracija i udar. Vibracija zdanij. Izmerenie vibracii i ocenka ee vozdejstvija na konstrukciju. Moscow: Standartinform (2008)

9. A.D. Zhigalin \& G.P Lokshin. Formirovanie vibracionnogo polja v geologicheskoj srede [The formation of the vibrational field in the geological sphere]. Inzhenernaja geologija [Engineering geology], 6, 110-119 (1991)

10. A. Vel'sovskij, B. Karpov, E. Smirnova. Development of a new method for checking frost heave in roads. Proceedings of the ICE - Civil Engineering, 168(5), 49-54 (2015). DOI: 10.1680/cien.14.00036

11. R. Smith, H. Hunt. Vibration of bell towers excited by bell ringing - a new approach to analysis. Proceedings of the $23^{\text {rd }}$ International Conference on Noise and Vibration Engineering, ISMA' 08, 9-15-2008 to 9-17-2008, Leuven, Belgium. P. Sas (ed.). Heverlee (Belgium): Katholieke Univ. Leuven. P. 699-714 (2008)

12. A.J. Frost. Towers and Bells. 2nd edn. Guildford, Surrey: Central Council of Church Bell Ringers (2006) 